\title{
The crossroads of magic and wellbeing: A review of wellbeing-focused magic programs, empirical studies, and conceivable theories
}

\author{
Steven Bagienski · Gustav Kuhn
}

\begin{abstract}
In recent years, magicians and scientists have begun collaborating to gain insight into various psychological functions. However, one underexplored area is the use of magic tricks to enhance wellbeing. Several past and current magic programs have been used to enhance cognitive, emotional, social, and physical wellbeing. The application of these wellbeing-focused magic programs ranges from physical and psychological therapies to gang prevention, hospitals and classrooms. A few have been empirically investigated and additional studies have also explored the wellbeing value of magic. These studies are reviewed in light of a proposed hierarchical model based on how magic was applied. Overall, methodologies need improvement but distinctions between levels of the hierarchy can still be observed and are discussed. Furthermore, the positive effects on wellbeing can also be organised into interrelated physical, cognitive, social, and affective components that reflect existing theoretical frameworks on wellbeing. To conclude, possible mechanisms and theoretical frameworks based on more established psychological theories are discussed in order to help guide future research.
\end{abstract}

Keywords: awe, broaden-and-build, curiosity, creativity, positive emotions, social skills, motivation, motor skills, magic tricks

\section{Introduction}

Magic is one of the most enduring forms of entertainment, and for thousands of years magicians have enchanted their audiences with their illusions. In recent years, magicians and scientists have started to collaborate in an attempt to develop a science of magic (Kuhn, Amlani, \& Rensink, 2008; Rensink \& Kuhn, 2015a; Rensink \& Kuhn, 2015b). This new approach has predominantly focused on magicians' deceptive methods and the emotional experiences magic evokes, in order to explore a wide range of psychological functions (Kuhn et al., 2008; Macknik et al., 2008; Thomas, Didierjean, Maquestiaux, \& Gygax, 2015). However, magic may also offer a valuable tool to enhance people's wellbeing in a wide range of areas. In recent years, several programs have been established that use magic to enhance both mental and physical wellbeing, but much of this work has been poorly documented and few connections have been drawn between these different approaches. Thus, the aim of this paper is to provide an up-to-date review of approaches that use magic to improve wellbeing and review them in light of the available empirical research. Moreover, we provide a novel progressive hierarchy that organises current research and intervention programs, which will hopefully prove useful as a framework for future research on magic and perhaps extend to many different fields, since magic draws upon expertise 
from a wide range of domains (Rissanen, Pitkänen, Juvonen, Kuhn, \& Hakkarainen, 2014). While there are likely some similarities with recent advances from other arts and wellbeing research (Fancourt, 2017), we hope this hierarchy proves particularly useful as a framework for future research on understanding these magic-based approaches to wellbeing and ultimately the most befitting applications.

The relationship to wellbeing can be partly understood by looking at the magical experience. Magic deals with fundamental psychological principles such as consciousness, belief, and free will (Kuhn et al., 2008; Macknik et al., 2008; Rensink \& Kuhn, 2015a; Thomas et al., 2015), yet the experience remains poorly understood. However, in recent years, interdisciplinary endeavours have started to uncover some key factors. Analyses from magicians (Ortiz, 1994), philosophers (Leddington, 2016), historians (Lamont, 2017), psychologists (Rensink \& Kuhn, 2015a; Rensink \& Kuhn, 2015b; Vidler \& Levine, 1981) and neuroscientists (Parris, Kuhn, Mizon, Benattayallah, \& Hodgson, 2009) all highlight one common explanation: magic elicits a conflict between what we believe to have experienced, and what we believe to be possible. This experience mirrors both Harris's (1994) work on child reactions to causal violations and Berlyne's (1954) distinction between epistemic and perceptual curiosity. The curiosity that naturally arises from this dissonance is particularly relevant to affective and cognitive domains of wellbeing. The affective components of the experience have also been described as a particular type of wonder (Lamont, 2017; Rensink \& Kuhn, 2015a), as pleasant, humorous, and highly memorable, due to intense curiosity (Leddington, 2016), and as surprise being a major component of the curiosity (Parris et al., 2009; Vidler \& Levine, 1981). Therefore, since knowledge-seeking positive emotions seem to be involved, watching magic tricks may enhance wellbeing via cognitive and affective domains. We will now shed light on some of these approaches, before discussing the empirical evaluations and theoretical frameworks.

\section{Wellbeing-focused magic programs}

There are currently many magic-based wellbeing programs implemented throughout health care. Open Heart Magic, for instance, uses magic as a means to console and empower hospitalised children by performing and teaching interactive close-up magic at bedsides so children can perform for family and staff (Hart \& Walton, 2010). This approach focuses on humour for its healing benefits, whereas the interactive nature makes it practical. Similarly, academics have written on how this interactive component could inform medical practitioners about building rapport (Kneebone, 2017), gaining trust, enhancing likeability, and becoming aware of nonverbal signals affecting patients' decisions (Sokol, 2008).

In rehabilitation, we also find programs that employ magic in physical therapy. Rehabracadabra, for instance, delivers workshops to occupational therapists on how to use magic tricks in physical therapy, with the aim of motivating clients, treating disorders, and constructing innovative, client-centred treatments (Fisher, 2016). Similarly, Healing of Magic is an American Occupational Therapy Association approved program that teaches therapists tricks to use in their practice (see Harte \& Spencer, 2014, for hand therapy analyses of the tricks). The program claims to facilitate daily living by improving attention, perception, cognition, motor skills, proprioception, speech, and psychosocial skills (Spencer, n.d.). David Copperfield's Project Magic also uses magic tricks as rehabilitative tools for physical, psychological, and social disabilities (Copperfield, 2013). Similarly, Breathe Magic motivates children with hemiplegia (a neuromuscular condition causing partial paralysis) to engage in intensive physical therapy by teaching them magic (Breathe Magic, n.d.). Rather than solely training therapists, however, 
Breathe Magic utilises magicians who work alongside therapists to incorporate therapeutic movements directly into the tricks.

Magic has also been used in prison rehab as a psychological therapy for addictions and maladaptive behaviour. Gareth Foreman's course combines magic with cognitive behavioural therapy (Foreman, 2016) to help disengaged prisoners to actively participate in therapy. For example, the therapist first performs a magic trick, after which they brainstorm solutions for the trick. This approach garners interest, acts as an ice breaker, and helps them identify strengths that can be used in more lawful ways of problem solving. Other combinations of magic with psychological therapy include school counselling (Bowman, 1986) and psychotherapy with children (Stehouwer, 1983).

In a similar vein, magic has been employed for societal wellbeing via gang and crime prevention. Streets of Growth is a charity that used street magic to gain trust with adolescents who are susceptible to a destructive future in gangs, drugs, and crime ("Darren Way," 2017; "Streets of Growth," 2017). The rationale is that individuals who are easily lured toward destructive lifestyles are also attracted to magic because both involve showing off and gaining credibility amongst a group through deception. Thus, the charity states that street magic can offer a valuable tool to connect with these youngsters and begin the process of building long-term relationships that lead to more promising futures for them.

Finally, magic has been applied in schools, especially for disabled students (see Figure 1 below). Hocus Focus is a curriculum designed to motivate students with learning difficulties by utilising magic tricks, which teachers incorporate into their lessons. The program states that the magic creates curiosity and enhances self-esteem by giving students skills that their non-disabled peers cannot perform (Spencer, 2011), which mirrors Frith and Walker's (1983) rationale of teaching magic to empower handicapped students. Others have suggested that magic would also be useful for teaching science (Österblom et al., 2015) and psychology (Solomon, 1980) to nondisabled students.

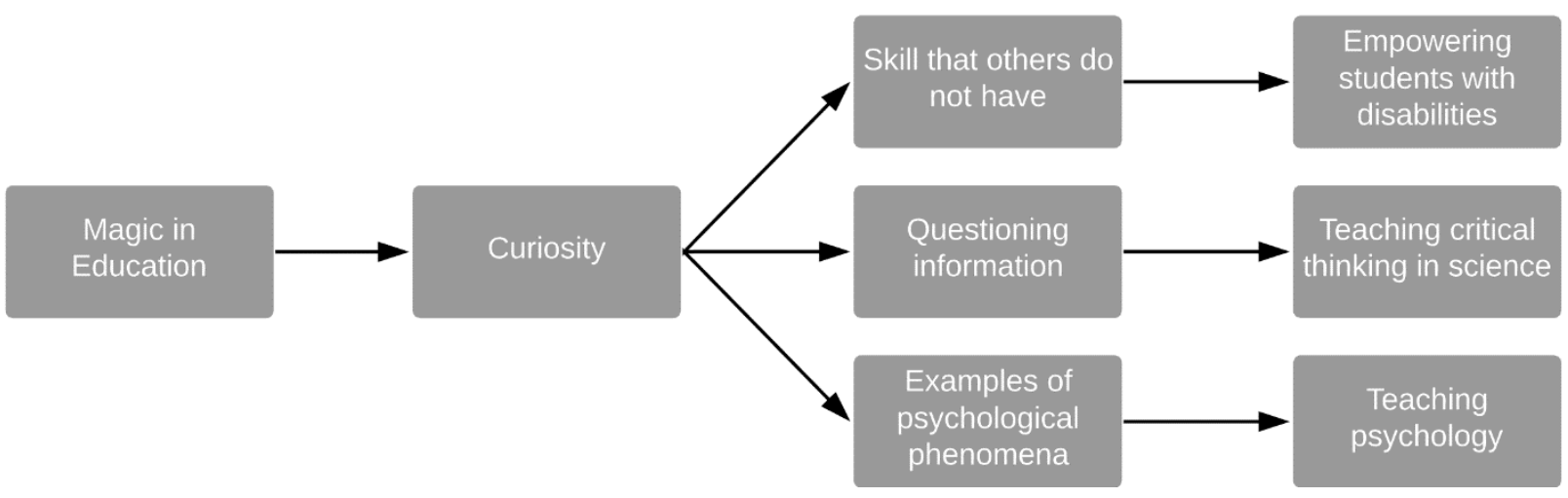

Figure 1. Rationales and applications of using magic tricks in education.

Whilst several active programs use magic to enhance wellbeing, only a few have been empirically evaluated (Green et al., 2013; Kwong \& Cullen, 2007; Spencer, 2012; Sui \& Sui, 2007), and few connections have been made between approaches. The focus of this paper now turns to evidence in support of using magic to enhance wellbeing from an empirical and theoretical perspective, whilst providing a new framework to categorise the various approaches. 


\section{Overview of empirical studies}

Despite the prevalence of active magic programs and suggestions from academics, the empirical evidence for using magic tricks to enhance wellbeing is still very young. To date, there has only been one review on the topic, but this was limited to health-care applications, found only eight empirical studies, presumed humour to be the only relevant positive emotion, and was mostly descriptive, offering little theoretical insight (Lam, Lam, \& Chawla, 2017). We propose a more general approach and will discuss research on magic and wellbeing progressively, using the hierarchical model depicted (see Figure 2 below), with each level acting as a foundation for the next.

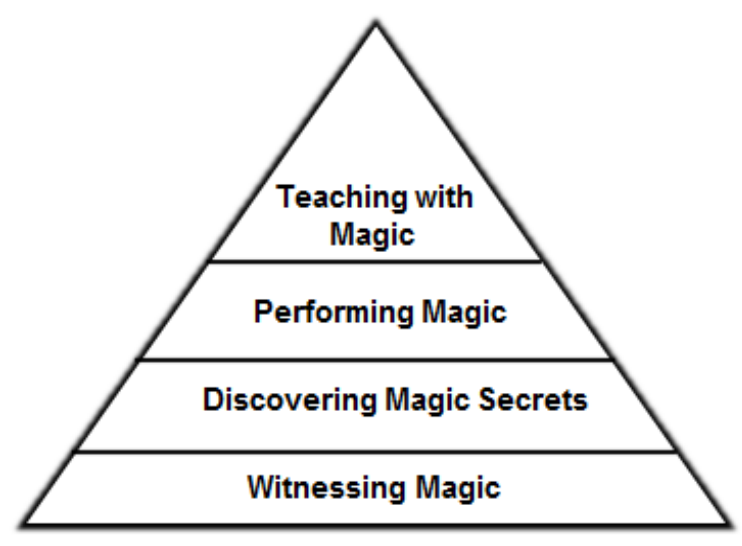

Figure 2. Progressive hierarchy stages for wellbeing effects of magic.

For example, witnessing a magic trick is required before learning its secret. Discovering the secret is required before one can perform magic. And performing experience is needed before one can teach with magic by integrating meaningful lessons or messages into the performance. Thus, this review begins with studies on witnessing magic (without revealing secrets) and builds to ones where participants use magic tricks to teach (see Table 1 below for details on samples, measures and effect sizes for the studies). ${ }^{1}$ This final stage pertains to the effects on the individual teaching with magic. This progressive structure also suggests that the wellbeing effects from higher levels build upon and retain the effects from lower levels. Finally, to better understand distinctions between levels, these wellbeing effects are broadly organised into affective, cognitive, physical and social domains.

${ }^{1}$ Details of the systematic processes used to collate empirical studies can be found in the supplementary material. 

(1) IT 1 Bagienski, S., \& Kuhn, G. (2019). The crossroads of magic and wellbeing: A review of wellbeing-focused magic programs, empirical studies, and conceivable theories

Table 1

Summary of the Quantitative Measures Used, Types of Analyses, and Effect Sizes in Each Study

\begin{tabular}{|c|c|c|c|c|}
\hline Reference & Sample size \& type & Quantitative measures & Analyses & $\begin{array}{l}\text { Statistical results with effect sizes } \\
\text { (if applicable) }\end{array}$ \\
\hline \multicolumn{5}{|l|}{ Witnessing Magic } \\
\hline Labrocca \& Piacentini (2015) & $\begin{array}{l}\mathrm{N}=100 \text { three to twelve-year- } \\
\text { olds }\end{array}$ & $\begin{array}{l}\text { Oucher scale (Beyer, Denyes, } \\
\text { Villarruel, 1992) to categorise } \\
\text { if they felt venepuncture } \\
\text { pain }\end{array}$ & Fisher's exact test & $\mathrm{p}=0.0163,{ }^{*} \varphi=0.261$ \\
\hline Lustig (1994) & $N=266$ self-selected students & $\begin{array}{l}\text { 5-point Likert items } \\
\text { assessing AIDS knowledge } \\
\text { and self-efficacy in } \\
\text { prevention behaviours } \\
\text { before and after magic show }\end{array}$ & $t$-tests on Likert items & $\begin{array}{l}\text { Knowledge items: } \\
\text { Mosquitoes }\left(\mathrm{p}<.001,{ }^{*} \mathrm{~d}=0.383\right) \\
\text { Donate blood }\left(\mathrm{p}=.005,{ }^{*} \mathrm{~d}=.319\right) \\
\text { Look sick }\left(\mathrm{p}=.007,{ }^{*} \mathrm{~d}=.304\right) \\
\text { Latex condom }\left(\mathrm{p}<.001,{ }^{*} \mathrm{~d}=.319\right) \\
\text { Take off condoms }(\mathrm{p}=0.446, \text { n.s. }) \\
\text { Self-efficacy items: } \\
\text { Refuse sex }\left(\mathrm{p}=.003, .{ }^{*} \mathrm{~d}=340\right) \\
\text { Buy condoms }(\mathrm{p}=.524, \text { n.s. }) \\
\text { Put on condoms }(\mathrm{p}<.001, * \mathrm{~d}=.319) \\
\text { Take off condoms }(\mathrm{p}=.446, \text { n.s. })\end{array}$ \\
\hline Moss, Irons, Boland (2017) & $\begin{array}{l}\mathrm{N}=224 \text { participants } \\
\text { crowdsourced from } \\
\underline{\text { www.microworkers.com }}\end{array}$ & $\begin{array}{l}\text { Need for cognition scale } \\
\text { (Cacioppo, Petty, Kao, 1984) } \\
\text { Engagement via absorption } \\
\text { subscale of Schoolwork } \\
\text { Engagement Inventory }\end{array}$ & $\begin{array}{l}\text { One-way ANCOVAs } \\
\text { controlling for age, sex, } \\
\text { and education }\end{array}$ & $\begin{array}{l}\text { Need for cognition: } \\
\qquad \mathrm{F}(3,217)=2.74, \mathrm{p}=.044, \eta^{2}=.0014 \\
\text { Engagement: }\end{array}$ \\
\hline
\end{tabular}




\begin{tabular}{|c|c|c|}
\hline & & $\begin{array}{l}\text { (Salmela-Aro, Upadaya, } \\
\text { 2012) }\end{array}$ \\
\hline & & $\begin{array}{l}\text { Comprehension test of } \\
\text { tutorial material (6-item } \\
\text { True/False) }\end{array}$ \\
\hline Peretz \& Gluck (2005) & $\begin{array}{l}\mathrm{N}=70 \text { three to six-year-olds } \\
\text { with strong-willed behaviour }\end{array}$ & $\begin{array}{l}\text { Time to dental chair } \\
\text { Ability to take dental } \\
\text { radiographs }\end{array}$ \\
\hline \multirow[t]{2}{*}{ Subbotsky (2010) } & $\begin{array}{l}\text { Experiment 1: Children } \\
\qquad \begin{array}{l}\mathrm{N}_{1}=28 \text { 4-yr-olds } \\
\mathrm{N}_{2}=28 \text { 6-yr-olds }(\mathrm{p}=.009) \\
\mathrm{N}_{3}=28 \text { 9-yr-olds }(\mathrm{p}=.0002)\end{array} \\
\text { Experiment } 2 \text { : Adults }\end{array}$ & $\begin{array}{l}\text { Curiosity measured as } \\
\text { proportion of participants } \\
\text { who wanted to explore a } \\
\text { magical vs counter intuitive } \\
\text { non-magical effect, with } \\
\text { varying levels of risk }\end{array}$ \\
\hline & $\begin{array}{l}\mathrm{N}=32 \text { college students } \\
\text { Experiment } 3 \text { : Adults } \\
\mathrm{N}=34 \text { college students } \\
\text { Experiment } 4 \text { : Adults }\end{array}$ & $\begin{array}{l}\text { Response frequencies of } \\
\text { whether or not participant } \\
\text { acknowledged the } \\
\text { possibility of true magic in } \\
\text { what they saw }\end{array}$ \\
\hline
\end{tabular}

$\mathrm{F}(3,217)=2.86, \mathrm{p}=.038, \eta^{2}=.0041$

Comprehension

$\mathrm{F}(3,217)<1, \mathrm{p}=.441, \eta^{2}=.0011$.

$t$-test for time to chair

Chi-square for radiographs

for

Time to dental chair $(\mathrm{p}=.001, * \mathrm{~d}=.864)$

Radiographs $\left(\mathrm{p}=.0013,{ }^{*} \varphi=0.261\right)$

\section{Fisher's exact tests}

$$
\begin{aligned}
& \text { Experiment 1: Children } \\
& \begin{array}{l}
\text { 4-yr-olds }\left(\mathrm{p}=.0007,{ }^{*} \varphi=0.658\right) \\
\text { 6-yr-olds }\left(\mathrm{p}=.009,{ }^{*} \varphi=0.512\right) \\
\text { 9-yr-olds }\left(\mathrm{p}=.0002,{ }^{*} \varphi=0.722\right)
\end{array}
\end{aligned}
$$

Experiment 2: Adults

College students $\left(\mathrm{p}=.003,{ }^{*} \varphi=0.529\right)$

Experiment 3: Adults

Higher risk $\left(p=.017,{ }^{*} \varphi=0.417\right)$

Highest risk ( $p=.08$, n.s.)

Experiment 4: Adults

Zero risk $(\mathrm{p}=.48, \mathrm{n.s}$.)

Possibility of magic $\left(\mathrm{p}<.001,{ }^{*} \varphi=1.215\right)$

Thinking Creatively in Two-way ANOVAs with Action and Movement Test summarised scores for (Torrance, 1981)

$$
\begin{aligned}
& \mathrm{N}_{1}=254 \text {-yr-olds } \\
& \mathrm{N}_{2}=276 \text {-yr-olds }
\end{aligned}
$$

Experiment 2

$\mathrm{N}_{1}=32$ 6-yr-old children

$\mathrm{N}_{2}=32$ 8-yr-old children
Blinded ratings of originality and non-reality for drawings of non-existent objects
Experiment 1, Main effects of film:

Fluency $\left(\mathrm{F}_{1,48}=14.14, \mathrm{p}<.001 ; \eta^{2}=0.2\right)$

Originality $\left(\mathrm{F}_{1,48}=21.11, \mathrm{p}<.001 ; \eta^{2}=0.3\right)$ Imagination $\left(F_{1,48}=73.66, \quad p<.001 ; \eta^{2}\right.$ $=0.6$ )

t-tests for drawings

Experiment 1, drawings by 6-yr-olds Originality score $(\mathrm{p}<.001 ; \mathrm{d}=2.2)$ Non-reality score $(\mathrm{p}<.001 ; \mathrm{d}=2.8)$ 


\section{Magical}

Questionnair

Thinking

(Bolton,

Dearsley, Madronal-Luque,

Baron-Cohen, 2002)

Vagnoli, Caprilli, Robiglio,

$\mathrm{N}=40$ Italian children Messeri (2005)
Two-way ANOVA for Magical Thinking scores
Modified Yale Preoperative Anxiety Scale (Kain et al., 1997) for child anxiety

State-trait Anxiety Inventory (Spielberger, 1983) for parent anxiety

Self Evaluation forms for clowns
One-way ANOVAs

Repeated-measures ANOVAs

Pearson correlation coefficients
Experiment 2, Main effects of film

Fluency $\left(\mathrm{F}_{1,60}=14.95, \mathrm{p}<.001 ; \eta^{2}=0.21\right)$

Originality $\quad\left(\mathrm{F}_{1,60}=22.63, \quad \mathrm{p}<.001 ; \quad \eta^{2}\right.$ $=0.27$ )

Imagination $\left(\mathrm{F}_{1,60}=21.82, \mathrm{p}<.001 ; \eta^{2}\right.$ $=0.27$ )

Experiment 2, drawings by 6-yr-olds Originality score $(\mathrm{p}<.01, \mathrm{~d}=1.5)$

Non-reality score $(\mathrm{p}<.05, \mathrm{~d}=0.7)$

Experiment 2, drawings by 8 -yr-olds No significant effects

In all experiments, no significant effects for:

\section{Interaction effects}

Magical thinking scores

Child anxiety during anaesthesia induction

${ }^{* *}\left(\mathrm{~F}_{1,38}=14.896 ; \mathrm{p}=.001,{ }^{*} \eta^{2}=.282\right)$

Control group anxiety increase

${ }^{* *}\left(\mathrm{~F}_{1,19}=21.253 ; \mathrm{p}=.001,{ }^{*} \eta^{2}=.999\right)$

Clown group correlation for child anxiety between waiting $\&$ induction room $(\mathrm{r}=0.93 ; \mathrm{p}<.001)$

Correlation of self-evaluations with child anxiety

Waiting room $(\mathrm{r}=0.83 ; \mathrm{p}<.001)$

Induction room $(\mathrm{r}=.77 ; \mathrm{p}<.001)$

No other significant correlations or effects with parent anxiety 


\begin{tabular}{|c|c|c|c|c|}
\hline Discovering Magic Secrets & & & & \\
\hline \multirow[t]{4}{*}{$\begin{array}{l}\text { Danek, Fraps, von Müller, } \\
\text { Grothe, Öllinger. (2014) }\end{array}$} & \multirow[t]{4}{*}{$\mathrm{N}=42$ adults } & \multirow{4}{*}{$\begin{array}{l}\text { Ratings on } 5 \text { dimensions of } \\
\text { insight } \\
\text { experienced }\end{array}$} & $\begin{array}{l}\text { Repeated measures } \\
\text { ANOVA }\end{array}$ & $\begin{array}{l}\text { Main effect of insight dimension } \\
{ }^{* *}\left(\mathrm{~F}_{4,41}=16.43, \mathrm{p}<.01, \eta^{2}=.268\right)\end{array}$ \\
\hline & & & $\begin{array}{l}\text { Pairwise post hoc } \\
\text { comparisons of highest } \\
\text { (happiness) and lowest } \\
\text { (impasse) rated }\end{array}$ & $\begin{array}{l}\text { Post hoc comparisons: } \\
\text { Happiness higher than all other } \\
\text { dimensions }(\mathrm{p}<.05)\end{array}$ \\
\hline & & & dimensions & $\begin{array}{l}\text { Impasse lower than all other } \\
\text { dimensions }\end{array}$ \\
\hline & & & & $(\mathrm{p}<.05)$ \\
\hline Hilas \& Politis (2014) & $\begin{array}{l}\mathrm{N}=77 \text { students ( } 34 \text { students } \\
\text { in control semester, } 33 \text { in } \\
\text { semester with new teaching } \\
\text { approach) }\end{array}$ & $\begin{array}{l}\text { 5-point Likert items in course } \\
\text { evaluation surveys }\end{array}$ & $\begin{array}{l}t \text {-tests between semesters } \\
t \text {-tests between average } \\
\text { of all other courses } \\
\text { within department }\end{array}$ & $\begin{array}{l}{ }^{* *} \text { Between semesters }\left(p=1.43 \mathrm{E}-05,{ }^{*} \mathrm{~d}=\right. \\
.456) \\
{ }^{* *} \text { Between courses }\left(\mathrm{p}=7.25 \mathrm{E}-08,{ }^{*} \mathrm{~d}=.586\right)\end{array}$ \\
\hline \multicolumn{5}{|l|}{ Performing Magic } \\
\hline Ezell \& Klein-Ezell (2003) & $\begin{array}{l}N=26 \text { children with } \\
\text { disabilities }\end{array}$ & $\begin{array}{l}\text { Self Image domain of } \\
\text { Student Self Concept scale } \\
\text { (Gresham, Elliott, Evans- } \\
\text { Fernandez, 1993) }\end{array}$ & $\begin{array}{l}\text { t-test comparing means } \\
\text { before and after } \\
\text { intervention }\end{array}$ & $\begin{array}{l}\text { Increase after intervention }(\mathrm{p}<.001, \mathrm{~d}= \\
.875)\end{array}$ \\
\hline \multirow[t]{2}{*}{ Green et al. (2013) } & $\mathrm{N}=22$ hemiplegic children & $\begin{array}{l}\text { Assisting Hand Assessment } \\
\text { (Holmefur, Aarts, } \\
\text { Krumlinde-Sundholm, 2009) }\end{array}$ & $\begin{array}{l}\text { Repeated } \\
\text { ANOVA }\end{array}$ & $\begin{array}{l}\text { Assisting Hand Assessment: } \\
\qquad\left(\mathrm{F}_{2,19}=8.87, \mathrm{p}=.002, \eta^{2}=.48\right)\end{array}$ \\
\hline & & $\begin{array}{l}\text { Children's Hand Experience } \\
\text { Questionnaire } \quad \text { (Sköld, } \\
\text { Hermansson, Krumlinde- } \\
\text { Sundholm, Eliasson, 2011) }\end{array}$ & & $\begin{array}{l}\text { Children's Hand-use Experience } \\
\text { Questionnaire: } \\
\qquad\left(F_{2,19}=12.93, \mathrm{p}<.001, \eta^{2}=.58\right)\end{array}$ \\
\hline
\end{tabular}


Kwong \& Cullen (2007)

$\mathrm{N}=5$

Levin (2006)

Lyons \& Menolotto (1990)

Spencer (2012)*

Sui \& Sui (2007)
$\mathrm{N}=6$ resident adolescents in psychiatric hospital

$\mathrm{N}=32$ to 44 students

$\mathrm{N}=40$ schizophrenic and depressed patients
EuroQol EQ-5D Health Questionnaire (EuroQol Group, 2005)

Rosenberg Self-Esteem scale (Rosenberg, 1979)

Rand 36-Item Short-Form Health Survey (Ware \& Sherbourne, 1992)

Rosenberg Self-Esteem scale (Rosenberg, 1979)

Affect and meaning of magic via response frequencies after the intervention only

Hocus Focus Self-efficacy scale

Rosenberg Self-esteem scale

Chinese General SelfEfficacy scale (Chiu \& Tsang, 2004)

Personal Well-being Index (Cummins, Eckersley, Pallant, van Vugt, Misajon, 2003)

No significant interaction effects

$t$-tests before and after EuroQol EQ-5D $(p=0.20, n . s$. intervention

Rosenberg Self-Esteem scale $(p=0.20$, n.s. $)$

Rand Health Survey subscales: Energy/Fatigue $\left(\mathrm{p}=.02,{ }^{*} \mathrm{~d}=1.436\right)$ No significant changes for all other subscales

$\mathrm{n} / \mathrm{a}$

$\mathrm{n} / \mathrm{a}$

Not reported; only a visual graph of means reported

t-tests on overall score before and after intervention

$t$-tests on individual items of scales n/a significance testing not calculated

$\mathrm{n} / \mathrm{a}$ significance testing not calculated

n/a significance levels and means not explicitly reported

\section{Self-efficacy (n.s. for overall score)}

Question on identifying multiple solutions:

$(\mathrm{p}<.05, * \mathrm{~d}=.698)$

Personal Wellbeing Index $\left(\mathrm{p}<.05,{ }^{*} \mathrm{~d}=\right.$ 0.370)

Question on interpersonal
relationships:
$\left(\mathrm{p}<.05,{ }^{*} \mathrm{~d}=.482\right)$




\section{Purdue Pegboard Test}

(Desrosiers, Hebert, Bravo,

Dutil, 1995)
Question on society integration:

$$
\left(\mathrm{p}<.05,{ }^{*} \mathrm{~d}=.554\right)
$$

Purdue Pegboard

Left hand $\left(\mathrm{p}<.05,{ }^{*} \mathrm{~d}=.198\right)$

Right hand $\left(\mathrm{p}<.05,{ }^{*} \mathrm{~d}=.142\right)$

Both hands $\left(\mathrm{p}<.05,{ }^{*} \mathrm{~d}=.604\right)$

\section{Teaching with Magic}

Papalaskari et al. (2006)

Papalaskari et al. (2007)

Spencer $(2012)^{*}$ n/a Purely qualitative measures from focus groups and exit surveys

n/a Purely qualitative measures from focus groups and exit surveys

n/a Purely qualitative measures from teacher notes

\& surveys n/a no quantitative measures

n/a no quantitative measure

Note: For Lustig (1994), no standard deviations were reported, so effect size was calculated using degrees of freedom and t-statistic. An estimate of the t-statistic was obtained by using the quantile function in R statistical software. The abbreviation "n.s." indicates "not significant."

* Where effect sizes were not reported, we have manually calculated effect size from given data, if possible.

** These degrees of freedom or F statistics differ from what was reported in the original paper due to either typos or a likely misinterpretation of the analysis method used by the authors, which was confirmed via correspondence with the authors. 


\subsection{Witnessing magic}

The first level of the hierarchy is the simple act of witnessing a magic performance. We will now discuss and evaluate the empirical evidence for effects of witnessing magic, which include both affective and cognitive components of wellbeing, predominantly as creativity, heightened curiosity and the ways this curiosity has been applied.

Enhanced curiosity in response to impossible events was observed in a series of empirical experiments where magical explanations to an anomalous event (the disappearance or destruction of an object) elicited more curiosity than those without a magical explanation, for both children and adults (Subbotsky, 2010). Effect sizes were large (see Table 1) and the curiosity to explore the anomalous event was influenced by the amount of associated risk. Similarly, Harris (1994) reviewed studies of children's reactions to unexpected, impossible events (e.g. magic tricks), concluding that whilst surprise is an element, it is only one part of an evolving reaction that ultimately leads to efforts in explaining the impossible event. This drive to acquire knowledge is also a defining feature of Berlyne's (1954) theory of epistemic curiosity, and reflects the curiosity framework of Kashdan et al. (2018), namely, the dimensions of joyous exploration, deprivation sensitivity (drive to solve problems), and stress tolerance (willingness to embrace distress from mysterious events). Thus, feeling intensely curious appears to be a predominant response to witnessing magic.

This curiosity from magic has also been applied as a pain or behavioural management tool, where tricks are used as a distraction therapy. For example, Labrocca and Piacentini (2015) showed that distracting children with magic tricks can reduce venepuncture pain. Another study in the hospital setting entailed clowns performing tricks for children to reduce pre-operation anxiety (Vagnoli et al., 2005) in the waiting room and during anaesthesia. Researchers and staff found this entertainment to indeed relieve children's anxiety, but staff felt it may not be practical, due to the clowns' interference with operating room procedures.

Magic as a distraction technique has also been used by dentists to deal with difficult to manage, strong-willed children (Peretz \& Gluck, 2005). The experiment showed that magic tricks yielded significant improvements in the amount of time taken to enter the dental chair, the number of successful radiographs taken, and cooperativeness of children when compared to traditional "tell-show-do" techniques. The researchers did not investigate why it was effective but suggested that magic caused children to perceive the dentist as a playful and approachable ally, thus reducing anxiety at the core of the troublesome behaviour.

While enhanced curiosity appears to be characteristic of watching magic, this curiosity might be localised to the content within the trick itself, so care must be taken to ensure it does not distract from the intended focus, such as a teacher's lesson. Moss et al. (2017) investigated this effect by measuring (1) engagement during a lecture video, (2) motivation to think effortfully about an upcoming task (need for cognition), and (3) comprehension of the lecture content after participants first watched magic or circus videos, or did not watch videos. Results (see Table 1) indicated that not revealing the trick's secret decreased motivation to think effortfully but did not affect the comprehension test scores. The decreased motivation for effortful thinking was consistent with their hypothesis that ruminating on how the trick was done would distract from subsequent learning. Furthermore, engagement decreased when participants viewed the magic, which the authors attributed to the contrast of an interesting magic trick to less interesting lecture material. Therefore, while witnessing magic can enhance curiosity, it may not transfer to 
subsequent teachings, and a better approach may be embedding lessons directly into the trick's performance.

There is also evidence suggesting that witnessing magical content may enhance cognition through creativity. Subbotsky, Hysted, and Jones (2010) showed children films with either magical or non-magical content and found higher scores on creativity tests for participants who watched the magical scenes (see Table 1). While witnessing magical content and witnessing magic tricks are not identical (Lamont, 2017; Leddington, 2016), they do, however, share the same component of watching impossible events. If this impossible event is responsible for enhancing creativity, we would therefore expect this effect to also transfer over to magic tricks.

Watching magic tricks has also been applied to public health in the form of an AIDS themed magic show for teenage students (Lustig, 1994), which was shown to increase self-efficacy for condom usage, AIDS knowledge, and the ability to refuse sex with small to medium effect sizes (see Table 1). However, since questionnaires were administered immediately after the show, we know little about its long-term impact.

In sum, witnessing magic may prove beneficial in enhancing cognitive wellbeing through increased creativity, perhaps affective wellbeing through self-efficacy, and both affective and cognitive wellbeing through increased curiosity. This intense curiosity appears to be prevalent in witnessing magic, which has been used as a distraction to manage perceived pain (Labrocca \& Piacentini, 2015), anxiety (Vagnoli et al., 2005) or troublesome behaviour stemming from anxiety (Peretz \& Gluck, 2005). When this attention-grabbing aspect is used to teach, however, it does not necessarily transfer to subsequent information presented, especially if secrets are withheld.

\subsection{Discovering magic secrets}

The act of discovering secret knowledge, as in a magic trick, may also enhance affective wellbeing. Danek et al. (2014) used magic tricks to investigate insight experiences. Participants repeatedly watched magic tricks until they figured out the secret, and both quantitative affective measures and qualitative self-reports were administered. The qualitative measures showed themes of physiological arousal, cognitive aspects related to problem solving, and emotional aspects related to happiness, tension-release, or pride. Of the quantitative variables, happiness (as measured via analogue scales between "unpleasant" and "pleasant") was the most characteristic of these insight experiences. Since this happiness came from problem solving, it may enhance both affective and cognitive wellbeing during the magic learning process, but future studies are needed to clarify how this differs from simply being told secrets, with no active effort to discover secrets.

A more applied study used magic tricks to teach material in a computer science course (Hilas $\&$ Politis, 2014). The new teaching approach incorporated mathematical magic tricks, games, and drama as part of a new curriculum. They used a "mind-reading" trick where students mentally chose a number that the instructor could reliably reveal, with seemingly little information. Students were encouraged to discover how it worked, culminating with the instructor describing how the trick's secret utilised a computer science principle. Using a prior semester as the control, results showed significant increases in course evaluation scores (measuring positive affect as enthusiasm, interest, and motivation) with a medium effect size, raising it to the highest rated course in the department. While the inclusion of drama and games confounds effects from the magic trick, it is likely that at least some of the positive affect arose from discovering the secret to the magic trick (see Danek et al., 2014). 
Overall, discovering secrets of magic may increase wellbeing through happiness, exhibited as pride or tension-release (Danek et al., 2014). This distinction builds upon the review by Lam et al. (2017) which highlighted humour as the predominant affective component. The study by Danek et al. (2014), however, clearly shows that humour is not the only affective component, because videos were devoid of humour, yet still enhanced happiness. As noted earlier, this encouragement to figure out magic tricks was also a focus of Foreman's (2016) cognitivebehavioural therapy program and of Hilas and Politis's (2014) new teaching approach, which showed increased positive affect in course evaluation surveys. While more research would help clarify the wellbeing effects of discovering secrets of magic, the available evidence suggests an impact on cognitive and affective wellbeing when discovering secrets of magic.

\subsection{Performing magic}

Most of the empirical studies on magic and wellbeing involve teaching participants to perform magic. As will now be seen, higher wellbeing is observed in affective, cognitive, physical, and social domains in these studies.

The first is an empirical evaluation of the aforementioned Breathe Magic program, which delivers intensive physical therapy through magic lessons during a 2-week summer camp (Green et al., 2013). Researchers measured hand-use of hemiplegic children and found improvements with a large effect size in independently performing bimanual tasks with the hemiplegic hand at both the end of camp and a 3-month follow-up. Subsequent data collected by Breathe Magic suggests that these improvements were also maintained at 6-month follow-up assessments (Breathe Magic, n.d.). Beyond physical wellbeing, researchers also observed positive feedback from the children and noted the importance of the communal context.

Meanwhile, the Healing of Magic program was investigated in two studies. The first involved 11 acquired brain injury patients (Kwong \& Cullen, 2007) who were taught magic using the Healing of Magic manual and were interviewed about the program. Only five completed the quantitative questionnaires on quality of life, self-esteem, and general health, with results only showing significant improvement for items measuring participants' energy and fatigue levels. However, it is difficult to draw meaningful conclusions due to the small sample size.

The second study utilising the Healing of Magic program involved mentally ill patients (Sui $\&$ Sui, 2007). Hospital staff were trained on the therapeutic use of magic tricks, which they taught to patients. Researchers used a within-subject design to measure personal wellbeing, selfefficacy, and various motor skills. As outlined in Table 1, results showed small to medium effect sizes for personal wellbeing and motor skills. Although the overall score for the self-efficacy scale was non-significant, one particular question that did change significantly reflected divergent thinking, as also seen in the prior study on witnessing magic (Subbotsky et al., 2010). Interestingly, the personal wellbeing scores were also driven by questions about social skills instead of curiosity. Interviews also revealed that patients felt motivated and engaged, and experienced many positive emotions. Taken altogether, motor skill improvements were attributed to consistent physical practice, whereas affective benefits appeared to be socially and cognitively driven.

Another study in the psychiatric setting entailed psychotic patients learning and practicing tricks, culminating in a final performance (Lyons \& Menolotto, 1990). Researchers measured patients' affective perceptions and perceived benefits from the magic, with the highest rated 
affective item describing magic as "sociable." For the perceived benefits, the highest rated items were that it helped patients relax, learn something new, and feel worthwhile. However, the study had no statistical analyses, no pre-intervention measures, and a small, perhaps biased sample of only self-selected patients interested in magic. Furthermore, their illnesses may have created inaccurate responses. Despite the flawed methodology, however, it is interesting that affective measures showed sociability, mirroring results from Sui \& Sui's (2007) study. This social component of performing magic may be a reasonable focus for future experiments on psychiatric samples.

One final study in the psychiatric setting involved a sample of pre-adolescent boys (Levin, 2006). Again, participants learned, practiced, and performed magic tricks. Pre and post invention measures were taken, with results indicating numerical increases in self-esteem, and decreases in interpersonal boundary violations and timeouts. However, no confidence levels or significance tests were calculated, likely due to the small sample, thus warranting replication attempts with larger samples.

In the educational setting, Ezell and Klein-Ezell (2003) conducted an experiment with mentally and physically disabled elementary school students. Students were taught various magic tricks by older university students whose lessons followed Frith and Walker's (1983) guidelines on teaching magic to handicapped children. These university students provided encouragement, helped the children practice, and measured their self-confidence. When both felt confident, children were given opportunities to perform for younger students and non-disabled peers. Results showed significant increases in self-confidence with a large effect size, which was attributed to magic giving the children an exclusive skill that their non-disabled peers lacked. In summary, this study provides some evidence that performing magic can increase affective wellbeing in disabled students.

A more comprehensive study in the educational setting utilised the aforementioned Hocus Focus curriculum (Spencer, 2012) with disabled students in three separate schools. An array of measurements was taken, which included interviews, journals, the Rosenberg (1979) Self-esteem scale and the Hocus Focus Self-efficacy scale, which were taken before, midway through, and after the course. Teachers also completed student observations, kept anecdotal records, were interviewed about their experience, and filled out questionnaires. Questionnaires varied, based on what the specific school wanted to improve, such as cognitive ability, social behaviours, frustration tolerance, or self-advocacy skills.

Qualitative results from both teacher- and student-reported measures reflected improvements in affective, social, and cognitive wellbeing. Affective wellbeing was observed in themes of enhanced self-determination, self-esteem, motivation, and other positive behaviours. Social wellbeing was observed as better rapport with students, better leadership and social skills, positive peer relationships, more participation, and students mentoring each other. Cognitive wellbeing was observed as improvements in engagement, concentration, memory, ability to follow directions, and curiosity (as already seen in witnessing magic). However, the social skill improvements were seen only in the schools that included the performing aspects, thus suggesting that social wellbeing only emerges from performing magic.

Overall, Spencer's study (2012) provides good qualitative evidence for using magic to enhance wellbeing in affective, social, and cognitive domains for a diverse sample of disabled students. Unfortunately, the quantitative evidence was only reported in a visual graph and only for one school. Further limitations include inconsistent methodologies between schools and no 
statistical significance testing, mirroring shortcomings in two of the psychiatric studies (Levin, 2006; Lyons \& Menolotto, 1990).

In summary, social and motor skill benefits emerge when participants perform magic, while also retaining some affective and cognitive benefits from witnessing magic and discovering its secrets. Many different approaches have been used, but only a few studies (Green et al., 2013; Ezell \& Klein-Ezell, 2003; Sui \& Sui, 2007) had reasonable quantitative methodologies. This is not to say that the ample qualitative evidence (e.g. Spencer, 2012) is to be disregarded, but rather, that initial evidence shows enough positive effects to warrant further research.

\subsection{Teaching with magic}

Only a few empirical studies investigated the wellbeing effect on the teacher when implementing magic. First were the teacher interviews from Spencer's study (Spencer, 2012), which revealed that teachers felt more confident and effective at teaching, as well as more job satisfaction from both their own personal growth and the personal growth they contributed to within their students.

The second study utilised a 2-week summer camp designed to attract and retain student interest in science, technology, engineering, and mathematics careers (Papalaskari et al., 2006; Papalaskari et al., 2007). For the first week, older children were trained to mentor younger apprentices by learning science, theatre, magical illusions, and problem solving. These skills were used to create educational performances that centred around a Harry Potter inspired, "American School of Magic" theme. During the second week, these young mentors used their performances to teach science to apprentices, which embedded scientific explanations directly into the tricks. Results from exit surveys and focus groups showed that mentors gained a deeper appreciation for science, theatre, and teaching careers, while both mentors and apprentices found it to be entertaining, exciting, and intensely enjoyable. Since these interviews were purely qualitative and only taken after the intervention, methodology was rather weak and it was difficult to draw firm conclusions. Nevertheless, one similarity we see in both of these approaches is a deeper appreciation of teaching, perhaps from witnessing the positive impact they had on their students.

\section{Discussion}

Applications for magic to enhance wellbeing in physical, affective, cognitive, and social domains are evident throughout both active programs and emerging empirical studies. These domains reflect some physical health outcomes in addition to the elements of wellbeing from Seligman's (2011, pp 16-25) wellbeing theory, namely, Positive Emotion, Engagement, Relationships, Meaning and Accomplishment (PERMA). We propose a progressive hierarchical model of magic and wellbeing that progresses from watching magic to teaching with magic. This model reveals unique benefits emerging at each stage, with at least some benefits retained and accumulated when moving up the hierarchy (Figure 2), namely, divergent creativity (Sui \& Sui, 2007; Subbotsky et al., 2010) and qualitative evidence on the similar constructs of pride (Danek et al., 2014), self-confidence (Ezell \& Klein-Ezell, 2003), and self-esteem (Spencer, 2012).

In the first stage of witnessing magic, positive emotions and engagement are exhibited as curiosity, interest, and its application as a distraction therapy. In the next stage, positive emotions and accomplishment are seen as happiness stemming from pride and tension-release when secrets are discovered. Additional improvements in social and motor skills only emerge once participants reach the stage of performing magic, which reflects relationships and perhaps more 
accomplishment in terms of the PERMA framework (Seligman, 2011). One distinction between stages is that the use of magic as a curiosity-inspired distraction tool helps manage difficult children with inflated self-esteem, whereas learning to perform magic helps uplift children with low self-esteem. Only two studies investigated effects of teaching with magic where the only distinct benefit from prior stages was a deeper appreciation for teaching, which may reflect meaning in the PERMA framework (Seligman, 2011) because the teachers saw the positive impact contributed to their students.

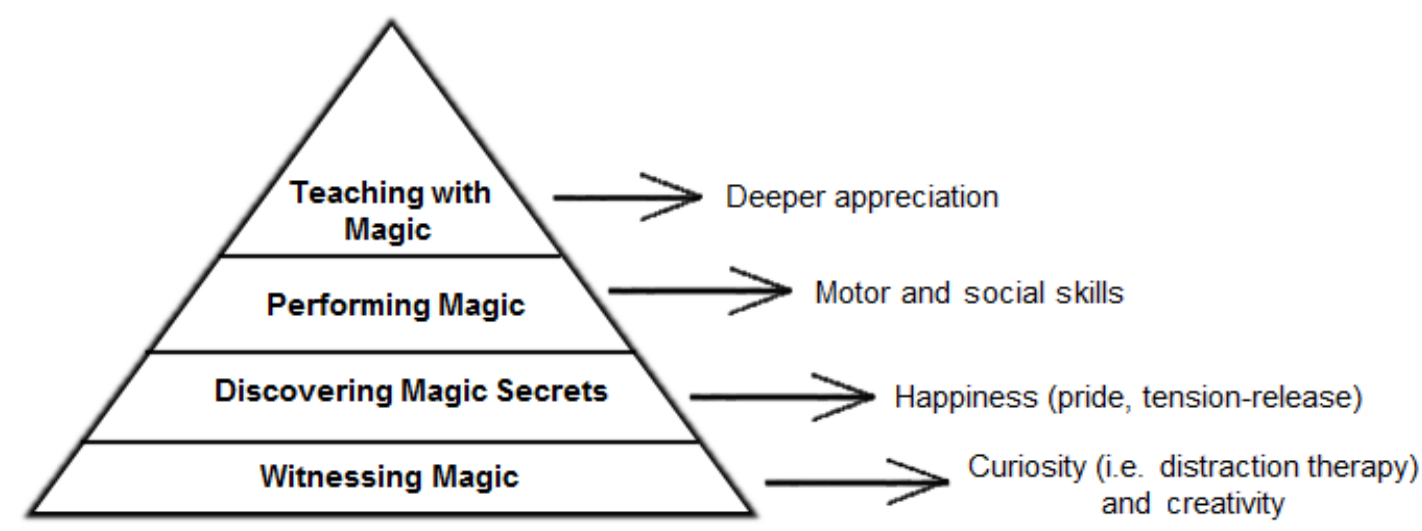

Figure 3. Magic and wellbeing hierarchy, highlighting the unique benefits that emerge in each stage in addition to those from lower stages.

These observations are not surprising, since elements of PERMA are moderately correlated (Goodman, Disabato, Kashdan, \& Kauffman, 2018), but we do hypothesise magic to be particularly unique and useful in the high degree of curiosity it inspires, due to its secretive nature, and in its frequent reliance on both astute social skills and a broad spectrum of motor movements. However, future research is still required, since many studies lack scientific rigour, do not control for third variables (e.g. humour, learning a new skill) and few investigated mechanisms for how magic specifically affects the building blocks of wellbeing.

Additionally, it is not clear whether certain benefits are more applicable for certain samples. For example, many samples involved children or handicapped individuals. However, some of the higher quality studies indicate that the ability to inspire intense curiosity (Subbotsky, 2010) and how that curiosity acts as a distraction (Labrocca \& Piacentini, 2015; Peretz \& Gluck, 2005; Moss et al., 2017; Vagnoli et al., 2005) are common in both healthy children and well-functioning adults who witness magic. Additionally, different types of curious people (Kashdan et al., 2018), might predict spectators who actively try to find the secret as opposed to those who watch passively. Finally, different genres of magic may yield different responses. Nevertheless, the current evidence will guide the remainder of this section, which discusses theoretical explanations that draw upon more established psychological research.

One overarching feature emerging from the empirical studies is the ability of magic to create curiosity and capture people's interest. This interest has been utilised in a range of domains, such as distraction therapies (Labrocca \& Piacentini, 2015; Peretz \& Gluck, 2005; Vagnoli et al., 2005), teaching in schools (Hilas \& Politis, 2014; Spencer, 2012), and physical therapies (Green et al., 2013) as an engaging and motivating tool. It is likely that these approaches create intrinsically motivated experiences, since fun and positive emotions are often present, which are intrinsically motivating and pursued for their own sake (Jayawickreme, Forgeard, \& Seligman, 2012). These experiences are also indicative of the joyous curiosity dimension in the curiosity framework of 
Kashdan et al. (2018), which relates to the joy of seeking out new knowledge and information. The other dimensions of curiosity might also be related, as discussed in the following sections, where different elements of wellbeing are considered, suggesting possible theoretical mechanisms at play in the hierarchy of magic and wellbeing.

\subsection{Witnessing magic}

As noted earlier, intense curiosity commonly results from witnessing magic. Curiosity, however, is more than an intellectually engaging phenomenon: it is an emotion that is often associated with positive affect via pleasurable exploratory processes (Csikszentmihályi, 1990; Kashdan et al., 2018; Kashdan, Rose, \& Fincham, 2004).

This pleasurable exploratory process seen in magic would be the joyous exploration dimension from Kashdan et al.'s (2018) recent work where they consolidate the different perspectives in curiosity research into a scale that gave five distinct dimensions. Their analysis indicated that this type had the second highest association with wellbeing measures. The dimension they found most associated with wellbeing is stress tolerance, which entails a willingness to embrace doubt or confusion that arises from unexpected or mysterious events. Witnessing magic is an unexpected (Parris et al., 2009) and mysterious event, yet these intense emotions are experienced in a safe and entertaining environment (Leddington, 2017). Thus, the enjoyment and wonder from magic might help condition people's attitudes toward uncertainty and help them embrace this uncertainty. How to best use the curiosity from magic in learning environments is still unclear, but one important factor might be whether lessons are embedded either within the trick's performance or within its secret, as suggested by Moss et al. (2017). Further evidence for this suggestion comes from Gruber, Gelman, \& Ranganath (2014), who showed that memory improved during states of high curiosity, and how students participate more when curious (Park, Tsukayama, Goodwin, Patrick, \& Duckworth, 2017). Therefore, embedding lesson material within the presentation or explanation of a trick (rather than afterwards) could be a fruitful avenue for future research.

Another positive emotion that witnessing magic might elicit is awe. Keltner and Haidt's (2003) framework of awe has two main components that are relevant to magic: a need to assimilate the experience into one's current mental structures and a perceived sense of vastness. The need for assimilation results from the cognitive conflict that is at the core of the magical experience (Lamont, 2017; Leddington, 2016; Rensink \& Kuhn, 2015a). The second condition of perceived vastness is also met, because, as a spectator watches an effective magic trick, every possible explanation that they imagine would be disproven (Lamont, 2017; Leddington, 2016; Ortiz, 1994; Rensink \& Kuhn, 2015a). Because of this, they become aware of a vast number of possible explanations that must exist, including an unknown correct one that exceeds their current knowledge. Thus, the spectator becomes cognisant of how limited their understanding truly is, even for very fundamental perceptions of our universe created by our senses. However, it is unclear whether this experience diminishes self-interest, as observed in other awe research (Bai et al., 2017), or whether it offers a unique exception. One possibility is that magic tricks elicit an emotion that lies at the intersection of awe and curiosity, namely, that of wonder. This positive emotion of wonder would align with both (1) observations of emotional gradients between awe and curiosity (Cowen \& Keltner, 2017), and (2) a theoretical framework by Pritchard (Billingsley, Abedin, \& Chappell, 2018) suggesting that the distinction between awe and wonder is that wonder has a participatory element.

Meanwhile, positive emotions may also explain how creativity increases from witnessing magic (Subbotsky et al., 2010). Creativity involves both divergent thinking where multiple ideas 
are generated, and convergent thinking where a selection from those ideas is made (Fürst, Ghisletta, \& Lubart, 2014). Subbotsky et al.'s (2010) study on watching magical content focused only on divergent thinking, which aligns with the Broaden-and-Build theory of positive emotions (Fredrickson, 1998). This theory argues that positive emotions exist in order to broaden mental resources and build them over time. In the case of witnessing magic, the positive emotion of curiosity would broaden by generating multiple imagined realities for a magical film (Subbotsky et al., 2010) or by generating multiple imagined solutions for a magic trick, thus creating a motivation to explore (Subbotsky, 2010). In both cases, curiosity comes from witnessing apparently impossible moments.

\subsection{Discovering the secret of magic}

The specific insight moment from discovering a trick's secret was also associated with happiness, as measured by analogue scales ranging from "unpleasant" to "pleasant," with qualitative reports showing that these positive feelings came from tension-release and pride (Danek et al., 2014). This is consistent with literature on solving other types of insight problems (i.e. verbal, special, or mathematical puzzles), in that positive affect is a core characteristic of insight experiences (Canestrari, Branchini, Bianchi, Savardi, \& Burro, 2018; Topolinski \& Reber, 2010). Hilas \& Politis (2014) also explicitly instructed participants to discover the secret, and while the effect of this encouragement is still unclear, the urge to discover the secret might naturally be motivated by the curiosity from watching magic tricks, regardless of instruction.

Once the secret is discovered, an insight experience occurs, with the emotion of pride and a sense of accomplishment that seems to emerge at this stage. This pride, along with the initial curiosity, may then create desire in replicating the trick oneself, thus motivating the learning and performing of the trick.

\subsection{Performing magic}

One of the most apparent uses for learning and performing magic is to increase physical wellbeing through developing motor skills in physical therapy. Magicians use sleight of hand and carefully controlled body language to achieve the necessary deception for the magical effect. The sleights involve ultra-fine dextrous movements, whereas the magician's misdirection via his gaze, gestures, or body angle involves larger bodily movements. Because of this wide range of both fine and gross physical movements, the design of magic tricks can be effectively integrated with physical therapy exercises.

However, there is likely more than just the physical movements that can explain the physical health outcomes. The art of magic is a form of entertainment, and therefore witnessing magic contains a great deal of positive emotions, which may play a role in two ways. Firstly, these positive emotions would motivate individuals to carry out the monotonous tasks of physical therapy under the guise of fun and engaging magic lessons (presumably via curiosity, awe, or pride from insight experiences). Secondly, once the learning begins, the positive emotions themselves may contribute to physical health. Positive emotions have been linked to a wide range of beneficial physical health outcomes that may operate on fundamental physiological processes (Diener, Pressman, Hunter, \& Delgadillo-Chase, 2017). These include resistance to infectious disease (Cohen, Alper, Doyle, Treanor, \& Turner, 2006), reduced risk of heart disease (Davidson, Mostofsky, \& Whang, 2010; Tindle et al., 2009) and lower all-cause mortality (Xu \& Roberts, 2010). Therefore, these beneficial physiological effects of positive emotions may also extend to physical therapy outcomes. If so, the presence of positive emotions when watching, learning, or performing magic tricks would further explain their effectiveness in enhancing 
physical wellbeing via motor skills (Green et al., 2013; Spencer, 2012; Sui \& Sui, 2007), and reducing venepuncture pain (Labrocca \& Piacentini, 2015).

Additionally, performing magic up close could be a good fit for enhancing social relationships by utilising social skills that encourage positive relationships (Spencer, 2012; Sui \& Sui, 2007). Two prominent features of positive relationships are the act of sharing good news and responding to it actively and constructively (Gable, Reis, Impett, \& Asher, 2004; Gable, Gonzaga, \& Strachman, 2006). These active constructive responses are characterised by enthusiasm and encouraging the bearer of good news to relive that moment, thus capitalising on the associated positive emotions. These responses may account for why the improved relationship skills emerged only in studies teaching participants to perform magic. As previously noted, magic tricks elicit curiosity, especially if a magical causation is suggested (Subbotsky, 2010). This curiosity reflects the constructive part of an active constructive response, where the person genuinely wants to learn more about the good news. In the case of magic, the "good news" is the ability to execute a trick successfully, which is shared by performing it. Moreover, surprise is a strong candidate for the experience of watching magic tricks (Harris, 1994; Parris et al., 2009; Vidler \& Levine, 1981). When this surprise is combined with positive affect, the resulting emotion resembles enthusiasm, which is the remaining part of an active constructive response. Therefore, the nature of performing magic tricks is hypothesised to enhance social wellbeing by encouraging active constructive responses, which cultivate positive relationships (Reis et al., 2010) and may partially explain the unique manner of how magical expertise is predominantly developed from informal social settings (Rissanen et al., 2014).

Once these active-constructive responses are initiated, the close-up magician will surely see the emotional reaction of spectators, because the deception for magic tricks often requires making eye contact. Eye contact also triggers mimicry of facial expressions between two individuals, which in turn creates a synergistic, embodied experience of the emotions (Niedenthal, Mermillod, Maringer, \& Hess, 2010). Therefore, the magician also experiences the spectator's positive emotions, which then reverberates back and forth between performer and spectators throughout the performance, thus creating an upward spiral of positive emotions. As a result, a positive rapport occurs, which could ultimately grow into meaningful relationships, as positive emotions are crucial for their formation (Waugh \& Fredrickson, 2006). The link between such relationships and lifetime psychological wellbeing is also well established (Lyubomirsky, King, \& Diener, 2005), so one mechanism for performing magic to increase wellbeing is hypothesised to be the cultivation of social relationships. One important distinction, however, is that these social wellbeing improvements would presumably be stronger for small, live audiences where eye contact is less restricted, compared to video-recorded or larger stage performances.

Other benefits of performing were increases in pride, confidence and self-esteem (Ezell, \& Klein-Ezell, 2003; Spencer, 2012; Sui \& Sui, 2007), but there are limitations on understanding their source. For example, pride may arise from a successful performance, or from successfully guessing secrets to magic tricks, as in Danek et al.'s (2014) study. It is also unclear whether these wellbeing benefits stem from practicing the tricks or performing them, since none of the studies controlled for this distinction.

\subsection{Teaching with magic}

One final, unclarified distinction is whether teaching with magic performances yields any unique benefits beyond those of performing magic. When children used magic to teach younger children, it resulted in deeper appreciation for the professions involved (Papalaskari 2006; Papalaskari, 2007). Similarly, the qualitative data from teachers in Spencer's (2012) study indicated a deeper appreciation of teaching. In both instances, the participants contributed an 
enjoyable learning experience to their students, which resembles the meaning element of the PERMA framework (Seligman, 2011), because meaning in this framework is indicative of serving something greater than the self (i.e. the students). Therefore, this meaningful appreciation of teaching might come from a noble sense of contribution rather than positive affect. While this may not necessarily be unique to magic, the added aspect of paying forward the benefits of witnessing magic to others nevertheless makes it a worthwhile line of future research.

\section{Conclusions and implications}

Magic is an ancient entertainment form, and in the last decade we have witnessed growing scientific interest in understanding the experience of magic (Leddington, 2016; Lamont, 2017; Rensink \& Kuhn, 2015a), as well as cognitive mechanisms that enable magicians to create these unique experiences (Kuhn, Caffaratti, Teszka, Rensink, 2014). The science of magic has started to build bridges between the scientific community and magicians' applied psychological knowledge and experience. As seen in this review, magic has also been used to enhance wellbeing in physical, affective, cognitive, and social domains throughout both active programs and emerging empirical studies. In both, we observe the use of magic as a motivating tool. A common application for these programs is physical therapy, but other settings include schools, hospitals, psychological therapy, and lifestyle intervention. Empirical studies show positive effects, but many have weak methodologies, warranting further research.

Despite the shortcomings, we have observed that witnessing magic enhances affective and cognitive wellbeing by inspiring intense curiosity and interest, which have been used as a distraction therapy. We believe that this ability to capture interest, along with feelings of awe, may be fundamental to the emotional experience of well-performed magic. This combination of curiosity and awe can be thought of as wonder. Thus, magic would be ideal for future research avenues on the scientific study of wonder. The timing for such research is also opportune, considering the recent strides in measuring both curiosity (Kashdan et al., 2018 ) and awe (Yaden et al., 2018). The implications of such research in positive psychology interventions are large, as the first step is capturing interest so that individuals can fully focus on what matters. Additionally, it is possible that the wellbeing benefits of curiosity and awe transfer to experiences of wonder. For curiosity, the dimensions most relevant might be joyous exploration, stress tolerance, or deprivation sensitivity, with the former two having strong associations with wellbeing (Kashdan et al., 2018). For awe, some wellbeing benefits include increased prosocial behaviour (Piff et al., 2015), enhanced attention (Sung \& Yih, 2016), decreased aggressive behaviour (Yang, Yang, Bao, Liu, \& Passmore, 2016), and creative benefits (Liberman, Polack, Hameiri, Blumenfeld, 2012). Other fruitful avenues in witnessing magic may include how individual differences in curiosity relate to the enjoyment of magic, as well as which factors in a performance lead to which types of curiosity.

Similarly, discovering secrets of magic was linked to wellbeing, as pleasant emotions from insight experiences. Performing magic builds upon these effects by showcasing improvements in social and motor skills, while retaining at least some aspects from prior stages. Thus, magic might be useful as an interesting and enjoyable type of social skills training for captivating team building experiences in the corporate space. Finally, using magic to teach might cultivate a deep sense of meaning and appreciation for one's teaching contributions. During each of these stages, there appears to be a sense of wellbeing, motivating progress toward the next stage. In this review, we offered a new framework that helps structure these different approaches, and also suggested some theoretical models that may account for the positive effects and potential hypotheses. 
Many avenues of magic and wellbeing are still largely unexplored. Well-designed experiments will help greatly in clarifying the psychological mechanisms at play. Moreover, we hope that the new theoretical insights in our understanding of magic will further help this process. Characterising the emotional and social experiences of magic would provide an excellent foundation, since magic is commonly used as an enjoyable, motivating tool in social settings. This solid foundation could then be used to investigate its interactions with physical or cognitive wellbeing, and further clarify whether wellbeing emerges through processes such as positive emotions and active-constructive responding, or perhaps guide us to more unexpected mechanisms. In doing so, the existing wellbeing-focused magic programs can better capitalise on the most useful aspects of magic tricks, professional entertainers can gain better professional opportunities, and perhaps new, more effective and more inclusive approaches will be created that help both the disadvantaged and the general public to lead more meaningful, flourishing lives.

\section{Authors}

Steven E. Bagienski

Goldsmiths, University of London, United Kingdom

stevebagienski@gmail.com

Gustav Kuhn

Goldsmiths, University of London, United Kingdom

G.Kuhn@gold.ac.uk

\section{Publishing Timeline}

Received 18 May 2018

Accepted 9 December 2018

Published 9 July

\section{References}

Bai, Y., Maruskin, L., Chen, S., Gordon, A., Stellar, J., McNeil, G., . . \& K Keltner, D. (2017). Awe, the diminished self, and collective engagement: Universals and cultural variations in the small self. Journal of Personality and Social Psychology, 113(2), 185-209.

Berlyne, D. (1954). A theory of human curiosity. British Journal of Psychology General Section, 45(3), 180-191.

Beyer, J. E., Denyes, M. J., \& Villarruel, A. M. (1992). The creation, validation, and continuing development of the Oucher: A measure of pain intensity in children. Journal of Pediatric Nursing, 7(5), 335-346.

Billingsley, B., Abedin, M., \& Chappell, K. (Eds.). (2018). A teacher's guide to science and religion in the classroom (pp. 46-57). Abingdon, England: Routledge.

Bolton, D., Dearsley, P., Madronal-Luque, R., \& Baron-Cohen, S. (2002). Magical thinking in childhood and adolescence: Development and relation to obsessive compulsion. British Journal of Developmental Psychology, 20(4), 479-494.

Bowman, R. P. (1986). The magic counselor: Using magic tricks as tools to teach children guidance lessons. Elementary School Guidance and Counseling, 21(2), 128-38.

Breathe Magic. (n.d.). http://breatheahr.org/knowledge/breathe-magic-intensive-therapy-foundation/

Cacioppo, J. T., Petty, R. E., \& Feng Kao, C. (1984). The efficient assessment of need for cognition. Journal of Personality Assessment, 48(3), 306-307.

Canestrari, C., Branchini, E., Bianchi, I., Savardi, U., \& Burro, R. (2018). Pleasures of the mind: What makes jokes and insight problems enjoyable. Frontiers in Psychology, 8, 2297. 
Chiu, F. P., \& Tsang, H. W. (2004). Validation of the Chinese general self-efficacy scale among individuals with schizophrenia in Hong Kong. International Journal of Rehabilitation Research, 27(2), 159-161.

Cohen, S., Alper, C. M., Doyle, W. J., Treanor, J. J., \& Turner, R. B. (2006). Positive emotional style predicts resistance to illness after experimental exposure to rhinovirus or influenza A virus. Psychosomatic Medicine, 68(6), 809-815.

Copperfield, D. (2013). Project Magic. https://www.projectmagic.org

Cowen, A. S., \& Keltner, D. (2017). Self-report captures 27 distinct categories of emotion bridged by continuous gradients. Proceedings of the National Academy of Sciences, 114(38), E7900-E7909.

Csikszentmihályi, M. (1990). Flow: The psychology of optimal experience. New York, NY: HarperCollins.

Cummins, R.A., Eckersley, R., Pallant, J., van Vugt, J. \& Misajon, R. (2003). Development of a national index of subjective wellbeing: The Australian Unity Wellbeing Index. Social Indicators Research, 64, 159-190.

Danek, A. H., Fraps, T., von Müller, A., Grothe, B., \& Öllinger, M. (2014). It's a kind of magic-what selfreports can reveal about the phenomenology of insight problem solving. Frontiers in Psychology, 5, 1408.

Darren Way Real Street Magic! (2017). Magicseen, 12(72), 28-31.

Davidson, K. W., Mostofsky, E., \& Whang, W. (2010). Don't worry, be happy: Positive affect and reduced 10-year incident coronary heart disease: The Canadian Nova Scotia Health Survey. European Heart Journal, 9, 1065-1070.

Desrosiers, J., Hebert, R., Bravo, G., \& Dutil, E. (1995). The Purdue Pegboard Test: Normative data for people aged 60 and over. Disability and Rehabilitation, 17(5), 217-224.

Diener, E., Pressman, S. D., Hunter, J., \& Delgadillo-Chase, D. (2017). If, why, and when subjective wellbeing influences health, and future needed research. Applied Psychology: Health and Well-Being, 9(2), 133-167.

EuroQol Group. (2005). EQ-5D: An instrument to describe and value health. http://www.euroqol.org

Ezell, D., \& Klein-Ezell, C. E. (2003). MAGICWORKS (motivating activities geared-to instilling confidencewonderful opportunities to raise kid's self-esteem). Education and Training in Developmental Disabilities, $38(4), 441-450$.

Fancourt, D. (2017). Arts in Health: Designing and researching interventions. Oxford, England: Oxford University Press.

Fisher, D. (2016). Rehabracadra. http://www.debbiefisher.org/magic-therapy

Foreman, G. (2016). The Use of Magic in Cognitive Behavioural Therapy. http://www.garethforemanmagic.co.uk/the-use-of-magic-in-therapy.html

Fredrickson, B. L. (1998). What good are positive emotions? Review of General Psychology, 2(3), 300-319.

Frith, G. H., \& Walker, J. C. (1983). Magic as motivation for handicapped students. Teaching Exceptional Children, 15(2), 108-110.

Fürst, G., Ghisletta, P., \& Lubart, T. (2014). Toward an integrative model of creativity and personality: Theoretical suggestions and preliminary empirical testing. The Journal of Creative Behavior, 50(2), 87108.

Gable, S. L., Gonzaga, G. C., \& Strachman, A. (2006). Will you be there for me when things go right? Supportive responses to positive event disclosures. Journal of Personality and Social Psychology, 91(5), 904-917.

Gable, S. L., Reis, H. T., Impett, E. A., \& Asher, E. R. (2004). What do you do when things go right? The intrapersonal and interpersonal benefits of sharing positive events. Journal of Personality and Social Psychology, 87(2), 228-245.

Goodman, F. R., Disabato, D. J., Kashdan, T. B., \& Kauffman, S. B. (2018). Measuring well-being: A comparison of subjective well-being and PERMA. The Journal of Positive Psychology, 13(4), 1-12.

Green, D., Schertz, M., Gordon, A. M., Moore, A., Schejter Margalit, T., Farquharson, Y., ... \& FattalValevski, A. (2013). A multi-site study of functional outcomes following a themed approach to handarm bimanual intensive therapy for children with hemiplegia. Developmental Medicine $\&$ Child Neurology, 55(6), 527-533.

Gresham, F. M., Elliott, S. N., \& Evans-Fernandez, S. E. (1993). Student self-concept scale. Circle Pines, MN: American Guidance Service. 
Gruber, M. J., Gelman, B. D., \& Ranganath, C. (2014). States of curiosity modulate hippocampus-dependent learning via the dopaminergic circuit. Neuron, 84(2), 486-496.

Harris, P. L. (1994). Unexpected, impossible and magical events: Children's reactions to causal violations. British Journal of Developmental Psychology, 12(1), 1-7.

Hart, R., \& Walton, M. (2010). Magic as a therapeutic intervention to promote coping in hospitalized pediatric patients. Pediatric Nursing, 36(1), 11.

Harte, D., \& Spencer, K. (2014). Sleight of hand: Magic, therapy and motor performance. Journal of Hand Therapy, 27(1), 67-69.

Hilas, C. S., \& Politis, A. (2014). Motivating students' participation in a computer networks course by means of magic, drama and games. Springer Plus, 3(1), 362.

Holmefur, M., Aarts, P., Hoare, B., \& Krumlinde-Sundholm, L. (2009). Test-retest and alternate forms reliability of the assisting hand assessment. Journal of Rehabilitation Medicine, 41(11), 886-891.

Jayawickreme, E., Forgeard, M. J., \& Seligman, M. E. (2012). The engine of well-being. Review of General Psychology, 16(4), 327-342.

Kain, Z. N., Mayes, L. C., Cicchetti, D. V., Bagnall, A. L., Finley, J. D., \& Hofstadter, M. B. (1997). The Yale Preoperative Anxiety Scale: How does it compare with a "gold standard"? Anesthesia \& Analgesia, 85(4), 783-788.

Kashdan, T. B., Rose, P., \& Fincham, F. D. (2004). Curiosity and exploration: Facilitating positive subjective experiences and personal growth opportunities. Journal of Personality Assessment, 82(3), 291-305.

Kashdan, T. B., Stiksma, M. C., Disabato, D. D., McKnight, P. E., Bekier, J., Kaji, J., \& Lazarus, R. (2018). The five-dimensional curiosity scale: Capturing the bandwidth of curiosity and identifying four unique subgroups of curious people. Journal of Research in Personality, 73, 130-149.

Keltner, D., \& Haidt, J. (2003). Approaching awe, a moral, spiritual, and aesthetic emotion. Cognition \& Emotion, 17(2), 297-314.

Kneebone, R. L. (2017). Performing magic, performing medicine. The Lancet, 389(10065), 148-149.

Kuhn, G., Amlani, A. A., \& Rensink, R. A. (2008). Towards a science of magic. Trends in Cognitive Sciences, 12(9), 349-354. http://dx.doi.org/10.1016/j.tics.2008.05.008

Kuhn, G., Caffaratti, H. A., Teszka, R., \& Rensink, R. A. (2014). A psychologically-based taxonomy of misdirection. Frontiers in Psychology, 5, 1392.

Kwong, E., \& Cullen, N. (2007). Teaching magic tricks to patients as an adjunct to their rehabilitation program. Poster presented at the Annual Scientific Meeting of the Canadian Association of Physical Medicine and Rehabilitation, Toronto, Canada.

Labrocca, G., \& Piacentini, E. O. (2015). Efficacia dei giochi di magia sul dolore da venipuntura: studio quasi sperimentale [Efficacy of magic tricks on venipuncture pain: A quasi-experimental study]. Children's Nurses: Italian Journal of Pediatric Nursing Science/Infermieri dei Bambini: Giornale Italiano di Scienze Infermieristiche Pediatriche, 7(1), 4-5.

Lam, M. T., Lam, H. R., \& Chawla, L. (2017). Application of magic in healthcare: A scoping review. Complementary Therapies in Clinical Practice, 26, 5-11.

Lamont, P. (2017). A particular kind of wonder: The experience of magic, past and present. Review of General Psychology, 21(1), 1-8.

Leddington, J. (2016). The experience of magic. The Journal of Aesthetics and Art Criticism, 74(3), 253-264.

Leddington, J. (2017). The enjoyment of negative emotions in the experience of magic. Behavioral and Brain Sciences, 40, E347.

Levin, D. M. (2006). Magic arts counseling: The tricks of illusion as intervention. Georgia School Counselors Association Journal, 13, 14-23.

Liberman, N., Polack, O., Hameiri, B., \& Blumenfeld, M. (2012). Priming of spatial distance enhances children's creative performance. Journal of Experimental Child Psychology, 111(4), 663-670.

Lustig, S. L. (1994). The AIDS prevention magic show: Avoiding the tragic with magic. Public Health Reports, 109(2), 162-167.

Lyons, M., \& Menolotto, A. M. (1990). Use of magic in psychiatric occupational therapy: Rationale, results and recommendations. Australian Occupational Therapy Journal, 37(2), 79-83. 
Lyubomirsky, S., King, L., \& Diener, E. (2005). The benefits of frequent positive affect: Does happiness lead to success? Psychological Bulletin, 131(6), 803-855.

Macknik, S. L., King, M., Randi, J., Robbins, A., Teller, Thompson, J., \& Martinez-Conde, S. (2008). Attention and awareness in stage magic: Turning tricks into research. Nature Reviews Neuroscience, 9(11), 871-879.

Moss, S. A., Irons, M., \& Boland, M. (2017). The magic of magic: The effect of magic tricks on subsequent engagement with lecture material. British Journal of Educational Psychology, 87(1), 32-42.

Niedenthal, P. M., Mermillod, M., Maringer, M., \& Hess, U. (2010). The Simulation of Smiles (SIMS) model: Embodied simulation and the meaning of facial expression. Behavioral and Brain Sciences, 33(06), 417433.

Ortiz, D. (1994). Strong Magic: Washington, WA: Ortiz Publications.

Österblom, H., Scheffer, M., Westley, F. R., van Esso, M. L., Miller, J., \& Bascompte, J. (2015). A message from magic to science: Seeing how the brain can be tricked may strengthen our thinking. Ecology and Society, 20(4), 16.

Papalaskari, M. A., Hess, K., Kossman, D., Metzger, S., Phares, A., Styer, R., . . \& Wunderlich, F. (2006, October). PIVOTS: Service learning at the science, theatre \& magic boundary. In Proceedings of the Frontiers in Education. 36th Annual Conference (pp. 18-23). San Diego, CA: IEEE.

Papalaskari, M. A., Hess, K., Lagalante, A., Nadi, N., Styer, R., Way, T., \& Weinstein, R. (2007, October). Work in progress - Engineering the magic school creativity and innovation in context. In Proceedings of the 37th Annual Frontiers in Education Conference-Global Engineering: Knowledge Without Borders, Opportunities Without Passports (pp. S2B1-S2B2). Milwaukee, IL: IEEE.

Park, D., Tsukayama, E., Goodwin, G. P., Patrick, S., \& Duckworth, A. L. (2017). A tripartite taxonomy of character: Evidence for intrapersonal, interpersonal, and intellectual competencies in children. Contemporary Educational Psychology, 48, 16-27.

Parris, B. A., Kuhn, G., Mizon, G. A., Benattayallah, A., \& Hodgson, T. L. (2009). Imaging the impossible: An fMRI study of impossible causal relationships in magic tricks. Neuroimage, 45(3), 1033-1039. http://dx.doi.org/10.1016/j.neuroimage.2008.12.036

Peretz, B., \& Gluck, G. (2005). Magic trick: A behavioural strategy for the management of strong-willed children. International Journal of Paediatric Dentistry, 15(6), 429-436.

Piff, P. K., Dietze, P., Feinberg, M., Stancato, D. M., \& Keltner, D. (2015). Awe, the small self, and prosocial behavior. Journal of Personality and Social Psychology, 108(6), 883-889.

Reis, H. T., Smith, S. M., Carmichael, C. L., Caprariello, P. A., Tsai, F. F., Rodrigues, A., \& Maniaci, M. R. (2010). Are you happy for me? How sharing positive events with others provides personal and interpersonal benefits. Journal of Personality and Social Psychology, 99(2), 311-329.

Rensink, R. A., \& Kuhn, G. (2015a). A framework for using magic to study the mind. Frontiers in Psychology, 5. http://dx.doi.org/10.3389/fpsyg.2014.01508

Rensink, R. A., \& Kuhn, G. (2015b). The possibility of a science of magic. Frontiers in Psychology, 6. http://dx.doi.org/10.3389/fpsyg.2015.01576

Rissanen, O., Pitkänen, P., Juvonen, A., Kuhn, G., \& Hakkarainen, K. (2014). Professional expertise in magic - Reflecting on professional expertise in magic: An interview study. Frontiers in Psychology, 5. http://dx.doi.org/10.3389/fpsyg.2014.01484

Rosenberg, M. (1979). Conceiving the self. New York, NY: Basic Books.

Salmela-Aro, K., \& Upadaya, K. (2012). The Schoolwork Engagement Inventory: Energy, dedication, and absorption (EDA). European Journal of Psychological Assessment, 28(1), 60-67.

Seligman, M. (2011). Flourish. New York, NY: Simon \& Schuster.

Sköld, A., Hermansson, L. N., Krumlinde-Sundholm, L., \& Eliasson, A. (2011). Development and evidence of validity for the Children's Hand-use Experience Questionnaire (CHEQ). Developmental Medicine $\mathcal{E}$ Child Neurology, 53(5), 436-442.

Sokol, D. K. (2008). Medicine as performance: What can magicians teach doctors? Journal of the Royal Society of Medicine, 101(9), 443-446.

Solomon, P. R. (1980). Perception, illusion and magic. Teaching of Psychology, 7(1), 3-8. 
Spencer, K. (n.d.). Healing of Magic Workshop Info. http://www.magictherapy.com/continuingeducation/healing-of-magic-workshop-info/

Spencer, K. (2011). Introduction to Hocus Focus. http://www.hocusfocuseducation.com/hocusfocus/introduction-to-hocus-focus/

Spencer, K. (2012). Hocus focus: Evaluating the academic and functional benefits of integrating magic tricks in the classroom. Journal of the International Association of Special Education, 13(1), 87-99.

Spielberger, C. D. (1983). Manual for the State-Trait Anxiety Inventory STAI (form Y)("self-evaluation questionnaire"). Palo Alto, CA: Consulting Psychologists Press.

Stehouwer, R. C. (1983). Using magic to establish rapport and improve motivation in psychotherapy with children: Theory, issues, and technique. Psychotherapy in Private Practice, 1(2), 85-94.

Streets of Growth, Connecting Youth Intervention with Regeneration (2017). http://www.streetsofgrowth.org/

Subbotsky, E. (2010). Curiosity and exploratory behaviour towards possible and impossible events in children and adults. British Journal of Psychology, 101(3), 481-501.

Subbotsky, E., Hysted, C., \& Jones, N. (2010). Watching films with magical content facilitates creativity in children. Perceptual and Motor Skills, 111(1), 261-277.

Sui, P., \& Sui, M. (2007, December). Magic and mental illness. Paper presented at the International Health and Mental Health Conference. Hong Kong. http://www.magictherapy.com/research/magic-andmental-illness/

Sung, B., \& Yih, J. (2016). Does interest broaden or narrow attentional scope? Cognition and Emotion, 30(8), 1485-1494.

Thomas, C. C., Didierjean, A., Maquestiaux, F., \& Gygax, P. (2015). Does magic offer a cryptozoology ground for psychology? Review of General Psychology, 19(2), 117-128. http://dx.doi.org/10.1037/gpr0000041

Tindle, H. A., Chang, Y. F., Kuller, L. H., Manson, J. E., Robinson, J. G., Rosal, M. C., . . \& Matthews, K. A. (2009). Optimism, cynical hostility, and incident coronary heart disease and mortality in the Women's Health Initiative. Circulation, 120(8), 656-662.

Topolinski, S., \& Reber, R. (2010). Gaining insight into the "Aha" experience. Current Directions in Psychological Science, 19(6), 402-405.

Torrance, E. P. (1981). Thinking creatively in action and movement. Bensenville, IL: Scholastic Testing Service.

Vagnoli, L., Caprilli, S., Robiglio, A., \& Messeri, A. (2005). Clown doctors as a treatment for preoperative anxiety in children: A randomized, prospective study. Pediatrics, 116(4), e563-e567.

Vidler, D. C., \& Levine, J. (1981). Curiosity, magic, and the teacher. Education, 101(3), 273-75.

Ware, J. E., Jr, \& Sherbourne, C. D. (1992). The MOS 36-item short-form health survey (SF-36): I. Conceptual framework and item selection. Medical Care, 30(6), 473-483.

Waugh, C. E., \& Fredrickson, B. L. (2006). Nice to know you: Positive emotions, self-other overlap, and complex understanding in the formation of a new relationship. The Journal of Positive Psychology, 1(2), 93-106.

Xu, J., \& Roberts, R. E. (2010). The power of positive emotions: It's a matter of life or death-Subjective well-being and longevity over 28 years in a general population. Health Psychology, 29(1), 9-19.

Yaden, D. B., Kaufman, S. B., Hyde, E., Chirico, A., Gaggioli, A., Zhang, J. W., \& Keltner, D. (2018). The development of the Awe Experience Scale (AWE-S): A multifactorial measure for a complex emotion. The Journal of Positive Psychology, 1-15.

Yang, Y., Yang, Z., Bao, T., Liu, Y., \& Passmore, H. A. (2016). Elicited awe decreases aggression. Journal of Pacific Rim Psychology, 10, 1-13. 